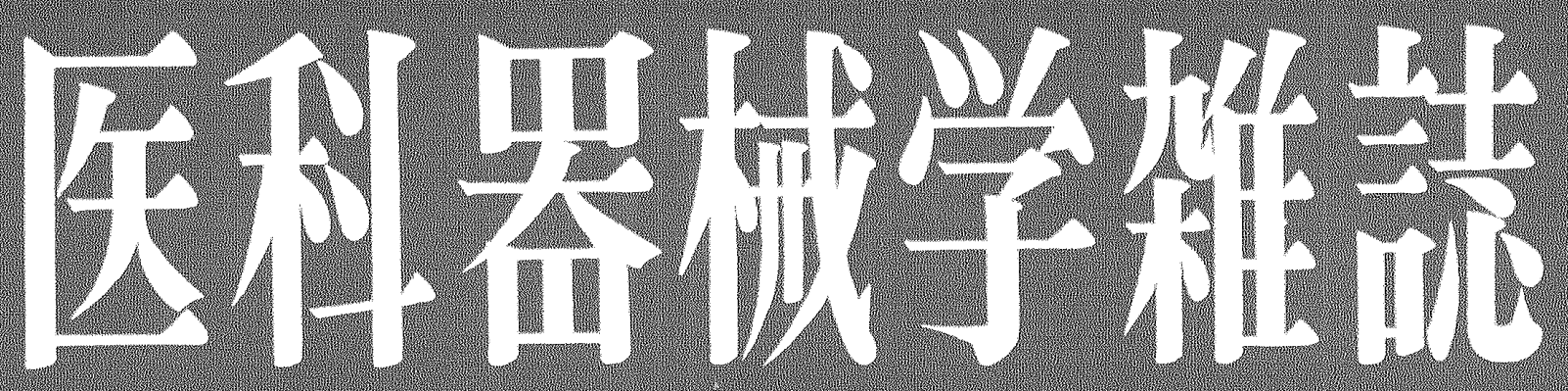

THE JOURNAL OF JAPANESE MEDICAL I NSTRUMENTS

\title{
Sept. 1973
}
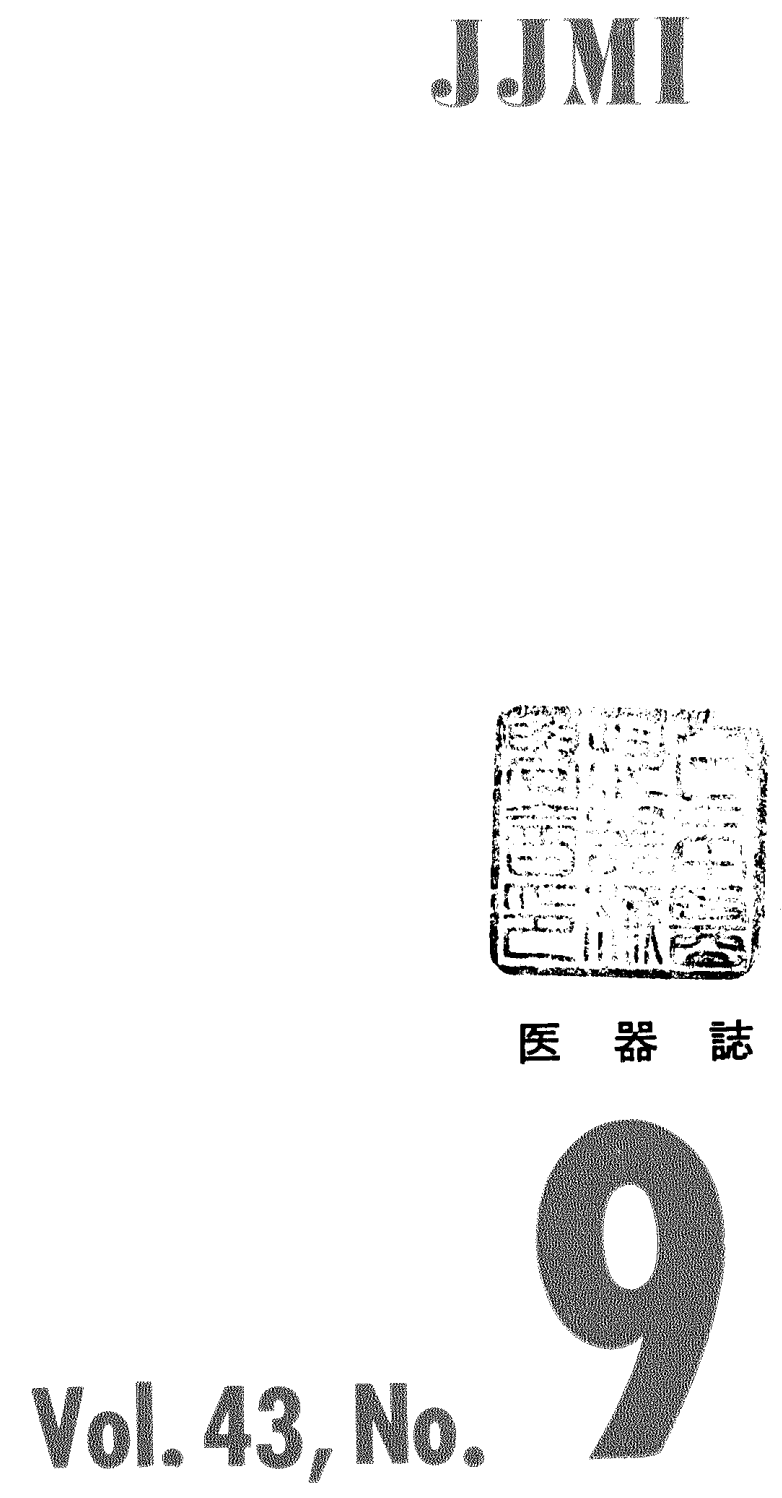

日本医科器械学会 